\title{
Uncontrolled hypertension based on morning and evening home blood pressure measurements from the J-HOME study
}

\author{
Taku Obara $^{1,2}$, Kie Ito ${ }^{1}$, Takayoshi Ohkubo ${ }^{1,3,4}$, Taku Shibamiya ${ }^{1}$, Takahiro Shinki ${ }^{1}$, Manami Nakashita ${ }^{1}$, \\ Azusa Hara $^{1}$, Hirohito Metoki ${ }^{1,5}$, Ryusuke Inoue ${ }^{6}$, Kei Asayama ${ }^{4}$, Masahiro Kikuya ${ }^{1}$, Nariyasu Mano ${ }^{2}$ \\ and Yutaka Imai, the J-HOME Study Group ${ }^{7}$
}

We evaluated the control condition of morning and evening home blood pressure (BP) and compared patients who had isolated uncontrolled morning hypertension and those who had sustained uncontrolled (morning and evening) hypertension using data from the Japan Home versus Office Blood Pressure Measurement Evaluation study. We evaluated 3303 treated hypertensive patients (mean age, $66.2 \pm 10.5$ years; men, 44.7\%) in Japan. We classified patients into controlled hypertension, isolated uncontrolled evening hypertension, isolated uncontrolled morning hypertension and sustained uncontrolled hypertension, based on the cutoff value of $135 / 85 \mathrm{~mm} \mathrm{Hg}$ for both morning and evening home BP. Of the 3303 patients evaluated, $24.6 \%$ had isolated uncontrolled morning hypertension, and $\mathbf{4 2 . 0 \%}$ had sustained uncontrolled hypertension. Factors associated with isolated uncontrolled morning hypertension included taking evening BP measurement after drinking alcohol or bathing. Factors associated with sustained uncontrolled hypertension were male gender, diabetes mellitus and renal disease. The regimen of antihypertensive medication was more complex in patients with uncontrolled morning hypertension than in controlled hypertension. Determinants of the difference between patients with isolated uncontrolled morning hypertension and those with sustained uncontrolled hypertension were diabetes mellitus, renal disease and lower prevalence in measuring evening BP after drinking alcohol or bathing. More than a half of the treated patients were classified into uncontrolled morning hypertension, which were associated with poorer prognosis. Classification of morning hypertensive patients into groups with or without evening hypertension may be useful for evaluating patients' total cardiovascular disease risk. Physicians should also consider evening BP measuring condition for adequate evaluation of evening BP values.

Hypertension Research (2009) 32, 1072-1078; doi:10.1038/hr.2009.152; published online 25 September 2009

Keywords: antihypertensive treatment; home blood pressure measurement; evening blood pressure; morning blood pressure

\section{INTRODUCTION}

As self-measured blood pressure (BP) at home (home BP) is performed under stable conditions, home BP can eliminate the 'whitecoat effect' resulting in better reproducibility and prognostic power, regardless of whether the subjects take antihypertensive drugs. ${ }^{1-4}$ Therefore, home BP measurement is a useful tool for the management of hypertension and the evaluation of cardiovascular risk..$^{5-7}$

In the Ohasama study, we reported that individuals with isolated uncontrolled morning hypertension (that is, patients whose evening home BP was properly controlled and morning home BP was not properly controlled) had a stroke risk similar to patients with sustained uncontrolled hypertension (that is, patients whose evening and morning home $\mathrm{BP}$ were not properly controlled). ${ }^{8}$ Previous reports showed, in detail, the usefulness of the classification using both morning and evening home BPs to characterize morning hypertension. $^{9-12}$ We also reported that not only morning home BP but also evening home $\mathrm{BP}$ was positively associated with the incidence of stroke. ${ }^{8,13}$ Therefore, evening home BP has clinical significance. However, few studies have monitored both morning and evening home BP among treated patients under controlled conditions, ${ }^{8,14}$ and no studies have clarified the factors that affect isolated uncontrolled morning hypertension (morning home BP is high but evening home

${ }^{1}$ Department of Clinical Pharmacology and Therapeutics, Tohoku University Graduate School of Pharmaceutical Sciences and Medicine, Sendai, Japan; ${ }^{2}$ Department of Pharmacy, Tohoku University Hospital, Sendai, Japan; ${ }^{3}$ Department of Planning for Drug Development and Clinical Evaluation, Tohoku University Graduate School of Pharmaceutical Sciences, Sendai, Japan; ${ }^{4}$ Tohoku University 21st Century COE Program 'Comprehensive Research and Education Center for Planning of Drug Development and Clinical Evaluation', Sendai, Japan; ${ }^{5}$ Department of Medical Genetics, Tohoku University Graduate School of Medicine, Sendai, Japan and ${ }^{6}$ Department of Medical Informatics, Tohoku University Graduate School of Medicine, Sendai, Japan

${ }^{7}$ See acknowledgement.

Correspondence: Dr T Ohkubo, Department of Planning for Drug Development and Clinical Evaluation, Tohoku University Graduate School of Pharmaceutical Sciences, Tohoku University Hospital, Sendai 980-8574, Japan.

E-mail: tohkubo@mail.tains.tohoku.ac.jp

Received 11 February 2009; revised 16 July 2009; accepted 4 August 2009; published online 25 September 2009 
$\mathrm{BP}$ is normal) or sustained uncontrolled hypertension (both morning and evening home BP are uncontrolled).

The objective of this report is to evaluate the control condition of morning and evening home BPs using data from the Japan Home versus Office BP Measurement Evaluation (J-HOME) study. ${ }^{15}$ We also compare patients who have isolated uncontrolled morning hypertension and those who have sustained uncontrolled (evening and morning) hypertension.

\section{METHODS}

\section{Patients}

Details of the methods used in this study have been described previously. ${ }^{15,16}$ Briefly, in March 2003, 7354 physicians randomly selected from all over Japan were invited to take part in this project. Of the 1477 physicians who agreed to participate, 751 collected data for the study. By the end of August 2003, 3586 patients were enrolled. Of those, 66 were excluded because antihypertensive drugs were not prescribed. An additional 217 patients were excluded because of insufficient data regarding home and office $\mathrm{BP}$ values or patient characteristics. Thus, the study population consisted of 3303 hypertensive patients. The study protocol was approved by the Institutional Review Board of Tohoku University School of Medicine.

\section{Home BP measurements}

The patients used the following procedures specified in the Japanese guidelines for home BP measurements. ${ }^{7}$ They measured their own BP once every morning while seated, within $1 \mathrm{~h}$ of waking, after at least $2 \mathrm{~min}$ of rest (but before ingesting medications and breakfast) and once every evening just before bedtime, and recorded the results for a 2 -week period. ${ }^{7}$ The patients applied the cuff-oscillometric method using electronic arm-cuff devices from Omron Healthcare (Kyoto, Japan), A\&D (Tokyo, Japan), Terumo (Tokyo, Japan) and Matsushita Electric Works (Osaka, Japan). The Ministry of Health, Labour and Welfare of Japan has validated and approved all such devices available in this country. ${ }^{17}$ The actual models were not described by the doctors who participated in the study, but all devices for measuring BP used in this study were certified as having been adjusted to meet the standard of the AAMI (Association for the Advancement of Medical Instrumentation). ${ }^{17,18}$ The mean of all measurements recorded over the 2-week period was calculated for each patient and further analyzed.

\section{Office BP measurements}

A physician or a nurse measured the patient's office BP twice consecutively in the sitting position after a rest of at least 2 min at each regularly scheduled visit. Office BP was measured using either the auscultatory method with a mercury or aneroid sphygmomanometer, or the cuff-oscillometric method with an electronic arm-cuff device that had been validated and approved by the Ministry of Health, Labour and Welfare, Japan. All automatic devices used in this study were certified as having been adjusted to the AAMI standard. ${ }^{18}$ The office BP value for each patient that was used for the analysis was defined as the average of four measurements taken at two office visits during the period when home measurements were being taken.

\section{Classification of subjects}

To evaluate the control condition of morning and evening home BPs, subjects were classified into the following four groups based on their morning and evening home BP levels: (1) controlled hypertension (morning and evening home systolic BP (SBP) $<135 \mathrm{~mm} \mathrm{Hg}$ and morning and evening home diastolic $\mathrm{BP}(\mathrm{DBP})<85 \mathrm{~mm} \mathrm{Hg}$ ); (2) isolated uncontrolled evening hypertension (morning home SBP $<135 \mathrm{mmHg}$ and morning home DBP $<85 \mathrm{~mm} \mathrm{Hg}$, and evening home SBP $\geqslant 135 \mathrm{~mm} \mathrm{Hg}$ and/or evening home DBP $\geqslant 85 \mathrm{~mm} \mathrm{Hg}$ ); (3) isolated uncontrolled morning hypertension (morning home SBP $\geqslant 135 \mathrm{~mm} \mathrm{Hg}$ and/or morning home DBP $\geqslant 85 \mathrm{~mm} \mathrm{Hg}$, and evening home SBP $<135 \mathrm{~mm} \mathrm{Hg}$ and evening home DBP $<85 \mathrm{~mm} \mathrm{Hg}$ ) and (4) sustained uncontrolled hypertension (morning home SBP $\geqslant 135 \mathrm{~mm} \mathrm{Hg}$ and/or morning home DBP $\geqslant 85 \mathrm{mmHg}$, and evening home SBP $\geqslant 135 \mathrm{~mm} \mathrm{Hg}$ and/or evening home DBP $\geqslant 85 \mathrm{~mm} \mathrm{Hg}$ ). The cutoff values of morning and evening home hypertension were based on several guidelines. ${ }^{19-21}$

\section{Data collection and statistical analysis}

Patient information was collected using a questionnaire administered by the attending physicians. Therefore, identification of family history and complications such as family history of hypertension, family history of cerebrovascular disease, stroke, ischemic heart disease, diabetes mellitus, renal disease, hypercholesterolemia and high uric acid were based on the attending physician's judgment. ${ }^{15}$ Dihydropyridine calcium-channel blockers (CCBs) were classified into two groups: 'amlodipine' and 'CCBs other than amlodipine'. Amlodipine was the most frequently prescribed medication in the J-HOME study; amlodipine is the most long acting of the CCBs. Therefore, we discriminated between amlodipine and the dihydropyridine CCBs other than amlodipine. The term 'CCBs other than amlodipine' in this study, therefore, indicates 'dihydropyridine CCBs other than amlodipine'. CCBs other than amlodipine included aranidipine, efonidipine, cilnidipine, nicardipine, nisoldipine, nitrendipine, nifedipine, nilvadipine, barnidipine, felodipine, benidipine and manidipine. On the basis of the patients' characteristics and their use of antihypertensive medications, univariate analysis was performed to determine which factors influenced isolated uncontrolled evening hypertension, isolated uncontrolled morning hypertension and sustained uncontrolled hypertension. The Bonferroni correction was applied for multiple comparisons. Multivariate logistic regression analysis was performed to obtain the best-fit model showing the most important independent variables. These variables were related to the difference between controlled hypertension and isolated uncontrolled evening hypertension, controlled hypertension and isolated uncontrolled morning hypertension, and controlled hypertension and sustained uncontrolled hypertension. We also determined the difference between patients with isolated uncontrolled morning hypertension and those with sustained uncontrolled hypertension. Variables were compared using Student's $t$-test and the $\chi^{2}$-test, as appropriate. Data were shown as mean \pm s.d. A $P$-value $<0.05$ was considered significant. All statistical analyses were conducted using the SAS package (Version 9.1; SAS Institute, Cary, NC, USA).

\section{RESULTS}

The mean age of the 3303 patients was $66.2 \pm 10.5$ years, and $44.7 \%$ were men. Overall, the mean morning home SBP/DBP was $139.8 \pm 13.9 / 81.8 \pm 9.5 \mathrm{~mm} \mathrm{Hg}$ and the mean evening home SBP/ DBP was $133.7 \pm 13.4 / 76.9 \pm 9.2 \mathrm{~mm} \mathrm{Hg}$ (Table 1). CCBs were used by $69.4 \%$ of patients, followed by angiotensin II receptor blockers in $43.6 \%$ and angiotensin-converting enzyme inhibitors in $16.7 \%$. The mean number of antihypertensive drugs prescribed per patient was $1.72 \pm 0.85$ (Table 2).

\section{Control condition of morning and evening home BPs}

Of the 3303 patients, $28.7 \%$ had controlled hypertension, $4.6 \%$ had isolated uncontrolled evening hypertension, $24.6 \%$ had isolated uncontrolled morning hypertension and $42.0 \%$ had sustained uncontrolled hypertension (Figure 1). Of these 3303 patients, the corresponding prevalence, based on SBP alone, was $34.1 \%$ with controlled hypertension, $5.2 \%$ with uncontrolled evening hypertension, $22.7 \%$ with isolated uncontrolled morning hypertension and $38.0 \%$ with sustained uncontrolled hypertension. The prevalence based on DBP alone was $62.8,2.6,19.6$ and $15.0 \%$, respectively. The prevalence of masked hypertension (that is, patients whose office BP was properly controlled and home BP was not properly controlled) based on morning home BP was $43.5 \%$ of isolated uncontrolled morning hypertension; the prevalence based on evening home BP was $50.3 \%$ of isolated uncontrolled evening hypertension.

\section{Controlled hypertension versus isolated uncontrolled evening hypertension}

Factors related to the difference between controlled hypertension and isolated uncontrolled evening hypertension could not be determined by univariate analysis (Tables 1 and 2). 
Table 1 Patients' characteristics according to the control condition of morning and evening home BPs

\begin{tabular}{|c|c|c|c|c|c|}
\hline $\mathrm{n}(\%)$ & $\begin{array}{c}\text { Total } 3303 \\
(100.0)\end{array}$ & $\begin{array}{c}\text { Controlled } \\
\text { hypertension } \\
948(28.7)\end{array}$ & $\begin{array}{c}\text { Isolated uncontrolled } \\
\text { evening hypertension } \\
153(4.6)\end{array}$ & $\begin{array}{l}\text { Isolated uncontrolled } \\
\text { morning hypertension } \\
814 \text { (24.6) }\end{array}$ & $\begin{array}{c}\text { Sustained uncontrolled } \\
\text { hypertension } \\
1388(42.0)\end{array}$ \\
\hline Age, years & $66.2 \pm 10.5$ & $65.2 \pm 10.1$ & $67.2 \pm 10.5^{*}$ & $66.7 \pm 10.0^{*}$ & $66.5 \pm 11.0^{*}$ \\
\hline Body mass index, $\mathrm{kg} \mathrm{m}^{-2}$ & $23.8 \pm 3.3$ & $23.4 \pm 3.5$ & $23.2 \pm 3.6$ & $23.7 \pm 3.1^{*}$ & $24.2 \pm 3.3^{* *}, \dagger \dagger$ \\
\hline Male, \% & 44.7 & 36.8 & $48.4^{*}$ & $50.3^{* *}$ & $46.4^{* *}$ \\
\hline Morning systolic BP, mmHg & $139.8 \pm 13.9$ & $125.9 \pm 6.3$ & $128.9 \pm 5.9 * *$ & $141.9 \pm 8.7^{* *}$ & $149.3 \pm 12.0^{* *}, \dagger \dagger$ \\
\hline Morning diastolic BP, mmHg & $81.8 \pm 9.5$ & $75.3 \pm 6.4$ & $75.6 \pm 7.4$ & $83.8 \pm 7.8^{* *}$ & $85.7 \pm 9.8^{* *}, \dagger \dagger$ \\
\hline Morning heart rate, bpm & $67.2 \pm 9.1$ & $66.7 \pm 8.6$ & $68.2 \pm 8.9$ & $66.5 \pm 9.0$ & $67.9 \pm 9.5^{*}, \dagger \dagger$ \\
\hline Evening systolic BP, mmHg & $133.7 \pm 13.4$ & $122.4 \pm 7.8$ & $139.4 \pm 6.1^{* *}$ & $126.5 \pm 7.1^{* *}$ & $145.1 \pm 10.1^{* *}, \dagger \dagger$ \\
\hline Evening diastolic BP, mmHg & $76.9 \pm 9.2$ & $71.9 \pm 6.8$ & $79.2 \pm 7.7^{* *}$ & $73.5 \pm 7.3^{* *}$ & $82.1 \pm 9.0^{* *}, \dagger \dagger$ \\
\hline Evening heart rate, bpm & $69.6 \pm 9.2$ & $68.8 \pm 8.4$ & $69.7 \pm 8.7$ & $69.9 \pm 9.7^{*}$ & $69.9 \pm 9.5^{*}$ \\
\hline Office systolic BP, mmHg & $142.8 \pm 14.4$ & $137.7 \pm 13.3$ & $140.1 \pm 14.3^{*}$ & $141.8 \pm 12.9 * *$ & $147.2 \pm 14.6^{* *}, \dagger \dagger$ \\
\hline Office diastolic BP, mmHg & $80.6 \pm 9.4$ & $78.5 \pm 8.8$ & $78.3 \pm 9.6$ & $80.5 \pm 9.0^{* *}$ & $82.4 \pm 9.5^{* *}, \dagger \dagger$ \\
\hline Habitual smoker, \% & 14.1 & 11.7 & 17.0 & 12.2 & $16.4^{*}, \dagger$ \\
\hline Habitual drinker, \% & 34.6 & 28.3 & 33.3 & $41.4^{* *}$ & $35.0^{* *}, \dagger$ \\
\hline Family history of hypertension, \% & 56.6 & 55.9 & 57.5 & 54.6 & 58.1 \\
\hline Family history of CVD, \% & 27.9 & 25.4 & 30.1 & 28.3 & 29.0 \\
\hline Stroke, \% & 9.0 & 7.6 & $13.1^{*}$ & 7.9 & $10.2^{*}$ \\
\hline History of IHD, \% & 8.3 & 6.5 & $12.4^{*}$ & 7.0 & $9.8^{*}, \dagger$ \\
\hline Diabetes mellitus, \% & 13.8 & 11.7 & 15.7 & 10.8 & $16.6^{* *}, \dagger \dagger$ \\
\hline Renal disease, \% & 5.2 & 4.1 & 4.6 & 3.6 & $7.0^{* *}, \dagger \dagger$ \\
\hline Hypercholesterolemia, \% & 40.5 & 38.9 & 45.1 & 39.8 & 41.4 \\
\hline High uric acid, \% & 11.5 & 9.0 & 11.1 & $13.4^{*}$ & $12.1^{*}$ \\
\hline \multicolumn{6}{|l|}{ Evening $B P$ measuring condition } \\
\hline After bathing, \% & 76.8 & 76.4 & 69.4 & $83.4^{* *}$ & $74.0+\dagger$ \\
\hline Before drinking, \% & 14.1 & 11.4 & $18.3^{*}$ & 12.9 & $16.2^{* *}$ \\
\hline After drinking, \% & 20.5 & 16.9 & 15.0 & $28.5^{* *}$ & $18.8+\dagger$ \\
\hline
\end{tabular}

Abbreviations: BP, blood pressure; CVD, cerebrovascular disease; IHD, ischemic heart disease.

${ }^{*} P<0.05$ versus controlled hypertension;

$* * P<0.00125$ versus controlled hypertension;

$\dagger P<0.05$ versus isolated uncontrolled morning hypertension;

$\dagger \uparrow P<0.00125$ versus isolated uncontrolled morning hypertention.

Due to multiple analyses performed, the level of significance has been adjusted according to Bonferroni; $P<0.00125$ is considered significant.

\section{Controlled hypertension versus isolated uncontrolled morning hypertension}

Multivariate logistic regression analysis was adjusted for variables that related to the difference between controlled hypertension and isolated uncontrolled morning hypertension. On the basis of this analysis, significant independent factors for isolated uncontrolled morning hypertension were measurement of evening home BP after bathing; measurement of evening home BP after drinking alcohol; taking three or more antihypertensive drugs; high frequency of taking antihypertensive drugs; taking CCBs other than amlodipine and taking $\alpha$-blockers (Table 3 ).

\section{Controlled hypertension versus sustained uncontrolled hypertension}

On the basis of multivariate logistic regression analysis, male gender, the presence of diabetes mellitus and renal disease, taking three or more antihypertensive drugs, a higher frequency of taking antihypertensive drugs, a higher prescription rate of CCBs other than amlodipine and a higher prescription rate of $\alpha$-blockers were determined to be significant and independent factors for sustained uncontrolled hypertension (Table 3 ).
Isolated uncontrolled morning hypertension versus sustained uncontrolled hypertension

The results of univariate analysis regarding the difference between patients with isolated uncontrolled morning hypertension and those with sustained uncontrolled hypertension are shown in Tables 1 and 2. On the basis of multivariate analysis, the presence of diabetes mellitus $(P=0.001)$ and renal disease $(P=0.003)$, and lower prevalence of measurement of evening home BP after drinking alcohol $(P<0.0001)$ or bathing $(P=0.0005)$ were found to be significant and independent factors associated with sustained uncontrolled hypertension.

\section{DISCUSSION}

In this study, we divided patients into four groups based on morning and evening home BP levels. We previously reported that $41.0 \%$ of patients had controlled hypertension, $5.4 \%$ had isolated uncontrolled evening hypertension, $14.5 \%$ had isolated uncontrolled morning hypertension and $39.1 \%$ had sustained uncontrolled hypertension among 504 treated patients in the Ohasama study. ${ }^{8}$ The difference in the prevalence of the various types of hypertension between these two studies may be attributed to the difference in the patients' age (the 
Table 2 Antihypertensive medication according to the control condition of morning and evening home BPs

\begin{tabular}{|c|c|c|c|c|c|}
\hline n (\%) & Total 3303 (100.0) & $\begin{array}{l}\text { Controlled } \\
\text { hypertension } \\
948(28.7)\end{array}$ & $\begin{array}{c}\text { Isolated uncontrolled } \\
\text { evening hypertension } \\
153 \text { (4.6) }\end{array}$ & $\begin{array}{l}\text { Isolated uncontrolled } \\
\text { morning hypertension } \\
814 \text { (24.6) }\end{array}$ & $\begin{array}{c}\text { Sustained } \\
\text { uncontrolled hypertension } \\
1388(42.0)\end{array}$ \\
\hline \multicolumn{6}{|l|}{ Class of antihypertensive drugs } \\
\hline CCBs (all), \% & 69.4 & 63.6 & 69.9 & $70.4^{*}$ & $72.8^{* *}$ \\
\hline DHP (amlodipine), \% & 37.7 & 39.6 & 35.3 & 39.4 & 35.7 \\
\hline DHP (other than amlodipine), \% & 29.3 & 21.6 & $32.0^{*}$ & $29.0 * *$ & $34.4^{* *}, \dagger$ \\
\hline ARBs, $\%$ & 43.6 & 42.1 & 38.6 & 43.2 & 45.4 \\
\hline ACEIs, \% & 16.7 & 14.7 & 13.7 & $18.2^{*}$ & 17.6 \\
\hline$\alpha$-blockers, \% & 13.4 & 8.8 & 11.8 & $14.5^{* *}$ & $16.1^{* *}$ \\
\hline$\beta$-blockers, $\%$ & 11.8 & 11.2 & 11.8 & 11.1 & 12.5 \\
\hline Diuretics, \% & 9.3 & 10.2 & 7.2 & 8.7 & 9.2 \\
\hline \multicolumn{6}{|l|}{ Number of antihypertensive drugs } \\
\hline Mean, $\mathrm{n}$ & $1.72 \pm 0.85$ & $1.57 \pm 0.75$ & $1.60 \pm 0.76$ & $1.73 \pm 0.85^{* *}$ & $1.82 \pm 0.91^{* *}, \dagger$ \\
\hline Three or more, \% & 16.0 & 11.6 & 10.5 & $17.0 * *$ & $19.0 * *$ \\
\hline Duration of treatment, months & $29.6 \pm 43.0$ & $29.4 \pm 38.6$ & $27.3 \pm 36.7$ & $30.5 \pm 44.1$ & $29.6 \pm 45.8$ \\
\hline \multicolumn{6}{|c|}{ Timing of administration of antihypertensive drugs } \\
\hline Only in the morning, \% & 68.1 & 77.1 & $62.1 * *$ & $66.6 * *$ & $63.4^{* *}$ \\
\hline Only in the evening, \% & 2.3 & 2.5 & 2.6 & 2.6 & 2.0 \\
\hline $\begin{array}{l}\text { Both in the morning and in the } \\
\text { evening, \% }\end{array}$ & 28.7 & 19.7 & $34.0 * *$ & $29.6^{* *}$ & $33.7^{* *}, \dagger$ \\
\hline
\end{tabular}

$n=3303$

\begin{tabular}{|c|c|c|}
\hline \multirow{2}{*}{$\begin{array}{c}\text { Morning } \\
\text { home BP } \\
135 / 85 \\
\mathrm{mmHg}\end{array}$} & $\begin{array}{c}\text { Isolated uncontrolled } \\
\text { morning hypertension } \\
24.6 \%(n=814)\end{array}$ & $\begin{array}{c}\text { Sustained Uncontrolled } \\
\text { hypertension } \\
42.0 \%(n=1388)\end{array}$ \\
\hline & $\begin{array}{c}\text { Controlled } \\
\text { hypertension } \\
28.7 \%(n=948)\end{array}$ & $\begin{array}{l}\text { Isolated uncontrolled } \\
\text { evening hypertension } \\
4.6 \%(n=153)\end{array}$ \\
\hline & & $\begin{array}{l}\text { רe BP } \\
\mathrm{n} \mathrm{Hg}\end{array}$ \\
\hline
\end{tabular}

Figure 1 Control condition of morning and evening home BPs. BP, blood pressure.

patients in the Ohasama study were $54 \pm 8$ years of age, whereas the patients in the J-HOME study were $65.8 \pm 10.0$ years of age), the study location (the Ohasama study evaluated a rural community in the northern part of Japan, whereas the J-HOME study was nationwide) or the different time period (the Ohasama study was conducted around 1990, whereas the J-HOME study was conducted in 2003). In addition, home BP measurement is very popular in Ohasama due to the introduction of home BP measurements for hypertension screening in 1986 in this region. Therefore, a higher proportion of subjects had experience in taking home BP measurements at the time of the Ohasama study, which may contribute to the finding of better control of morning and evening home BP in the Ohasama study compared with the J-HOME study.22
To our knowledge, this is the first report to clarify the difference between isolated uncontrolled morning hypertension and sustained uncontrolled hypertension. Factors associated with isolated uncontrolled morning hypertension included measurement of evening home BP after drinking alcohol or bathing, the number as well as class of antihypertensive drugs and the frequency of taking antihypertensive drugs. Factors associated with sustained uncontrolled hypertension were male gender, diabetes mellitus, renal disease, the number and class of antihypertensive drugs, and the frequency of taking antihypertensive drugs.

Evening measuring condition of BP was only associated with isolated uncontrolled morning hypertension. Drinking alcohol can have biphasic effects on BP. ${ }^{23,24}$ Kawano et al..$^{23,25}$ reported that the depressor effect of alcohol was observed for several hours after alcohol intake, regardless of the duration of alcohol consumption, but the morning pressor effect of alcohol was observed after 2 weeks of drinking. The pressor effect in the morning is based on repeated intake of alcohol for a certain period, which leads to an increase in peripheral vascular resistance and subsequent elevation of BP. ${ }^{24,26}$ The influence of bathing on evening BP was examined only in one previous study. ${ }^{27}$ Kawabe and Saito ${ }^{27}$ showed that the depressor effect of nighttime bathing was mainly due to its vasodilator action and was sustained for up to $60 \mathrm{~min}$ after bathing. Therefore, isolated uncontrolled morning hypertension might be the result of sustained uncontrolled hypertension, which had been modified by drinking alcohol or bathing before the evening home BP measurement.

Diabetes mellitus was a determinant of sustained uncontrolled hypertension. Although details of the mechanism have not been identified, in patients with noninsulin-dependent diabetes mellitus, hyperleptinemia and hyperinsulinemia may elevate BP through the sympathetic stimulation. ${ }^{28}$ In particular, there are some mechanisms 
Table 3 Multivariate logistic regression analysis for isolated uncontrolled morning hypertension and sustained uncontrolled hypertension

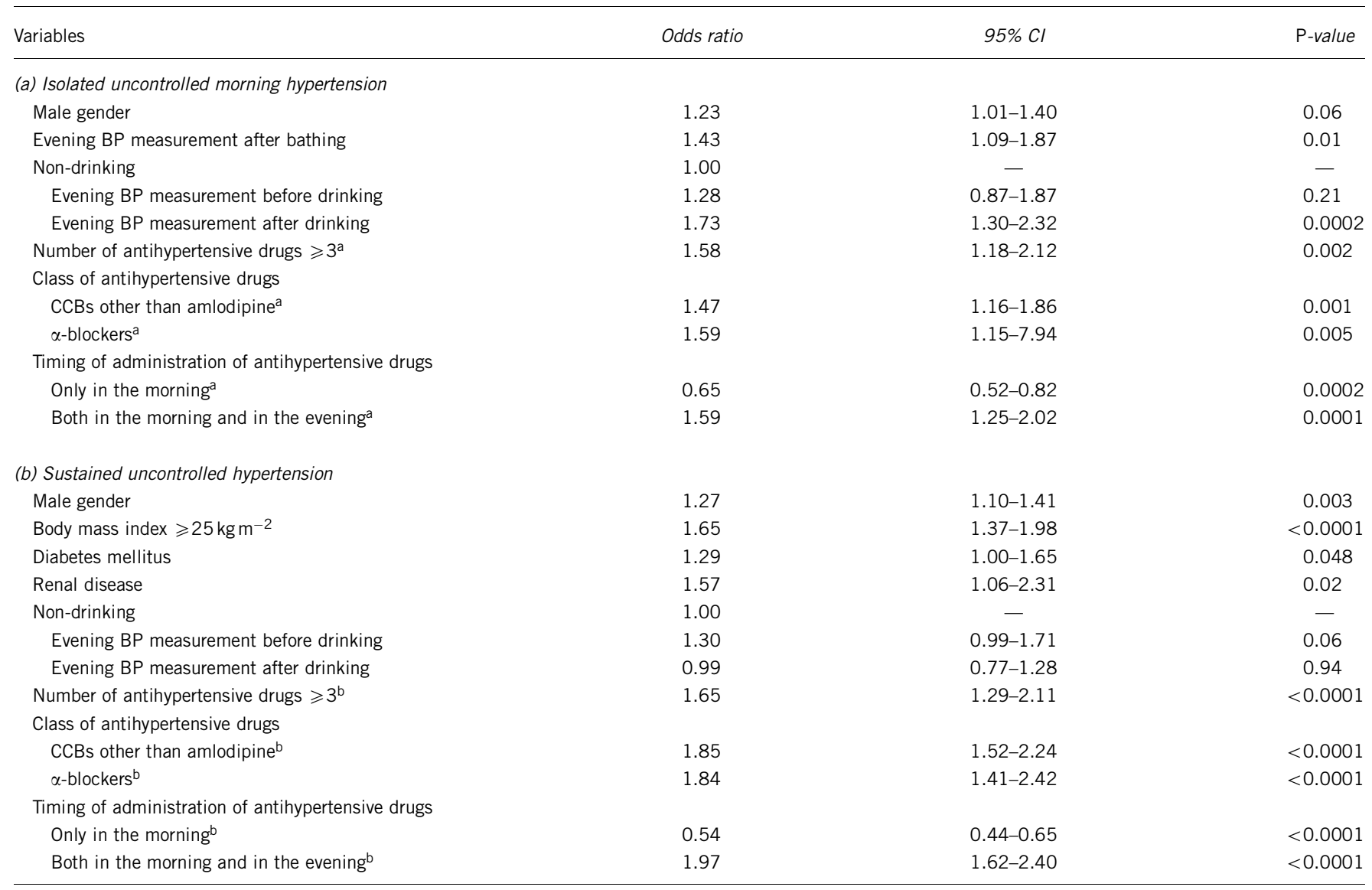

Abbreviations: $\mathrm{Cl}$, confidence interval; $\mathrm{BP}$, blood pressure; $\mathrm{CCBs}$, calcium-channel blockers. aAdjusted for evening home BP measuring condition.

bAdjusted for gender, body mass index, diabetes mellitus and renal disease.

that enhance endothelial dysfunction through an oxidative stress based on insulin resistance and hyperglycemia in diabetic patients. ${ }^{29,30}$ Therefore, as shown in previous studies, it is difficult to lower BP in diabetic patients to a target BP level. ${ }^{31}$ The enhancement of salt sensitivity of BP and excess of body fluid volume accompanying renal diseases could potentially be associated with uncontrolled hypertension. Therefore, in this study, the presence of renal disease may be a determinant of sustained uncontrolled hypertension. Previously, it has been reported that multiple drug combination therapy was necessary to achieve target BP levels in hypertensive patients with renal disease. ${ }^{32,33}$

A previous study reported that the insufficient duration of action of CCBs other than amlodipine induced uncontrolled morning BP in treated hypertensive patients. ${ }^{34}$ We also found that the prescription of CCBs other than amlodipine was also related to uncontrolled morning home BP. Of the patients given CCBs other than amlodipine in our study, 3.3\% took these CCBs just after awakening and $91.1 \%$ took them after breakfast. Therefore, it seems that the insufficient duration of action of CCBs other than amlodipine taken in the morning contributes to our finding of uncontrolled morning home BP. Several studies have reported that $\alpha$-blockers taken in the evening have their greatest effect in the morning when the sympathetic nervous system is extensively activated. ${ }^{35,36}$ In our study, of patients given $\alpha$-blockers, $39.7 \%$ took their $\alpha$-blockers after dinner and $26.8 \%$ took them before going to bed. Therefore, it is likely that $\alpha$-blockers are frequently prescribed to patients with intractable and uncontrolled morning home BP. The number of antihypertensive drugs and the frequency of taking antihypertensive drugs were higher in patients with uncontrolled morning home BP than those with controlled hypertension. These findings suggest that patients with uncontrolled morning home BP might receive a complex regimen of antihypertensive medications, as patients with uncontrolled morning hypertension might have severe or resistant hypertension. As the risk factors of sustained uncontrolled hypertension in this study were similar to the cause of home resistant hypertension reported previously, ${ }^{37}$ sustained uncontrolled hypertension in this study may, in part, be resistant hypertension.

In this study, we also found that patients with sustained uncontrolled hypertension had a higher proportion of total cardiovascular disease risk, such as diabetes mellitus and renal disease, compared with those with isolated uncontrolled morning hypertension. We previously reported that the stroke risk of patients with isolated uncontrolled morning hypertension and those with sustained uncontrolled hypertension were similar. ${ }^{8}$ However, differences in patient characteristics between the two groups suggest that total cardiovascular disease risk might also vary between these two groups. Therefore, further study is needed to clarify the total cardiovascular disease risk between patients with isolated uncontrolled morning hypertension and those with 
sustained uncontrolled hypertension, specifically with regard to the evening measurement of BP.

This study has some limitations. As this study used a cross-sectional design, we could not investigate the relationship between the timing of drug administration as well as elimination half-times of drugs versus the control condition of morning and evening home BPs. We also did not collect patients' drug compliance in this study. Drug compliance is essential in pharmaceutical care. As previous studies have reported that home BP measurements are associated with good medication compliance $^{38,39}$ and the present population measured home BP, patients' compliance might be better in the present population compared with that in other populations.

In conclusion, more than half of treated patients were classified into either isolated uncontrolled morning hypertension or sustained uncontrolled hypertension, which are both associated with poorer prognosis. These findings suggest that evaluation of morning home BP should take priority over the evaluation of evening home BP, as patients' high BP values might be underestimated evaluating only evening home BP. This study also suggests that classification of morning hypertensive patients into groups with or without evening hypertension may be useful to evaluate patients' total cardiovascular disease risk, as isolated uncontrolled morning hypertension and sustained uncontrolled hypertension might represent different characteristics of morning hypertension. However, physicians should also consider evening BP measurement for adequate evaluation of evening home BP values of hypertensive patients.

\section{CONFLICT OF INTEREST}

The authors declare no conflict of interest.

\section{ACKNOWLEDGEMENTS}

Members of the J-HOME Study Group

Principal Investigator: Yutaka Imai.

Advisory Committee: Masatoshi Fujishima (deceased), Takao Saruta. Steering Committee: Toshio Ogihara, Kazuaki Shimamoto, Toshiro Fujita, Kazuyuki Shimada, Toshio Ikeda, Iwao Kuwajima, Satoru Kuriyama, and Kazuomi Kario.

Coordinating and Data Management Center: Takayoshi Ohkubo, Taku Obara, Taku Shibamiya, Takahiro Shinki, Kie Ito, Kenta Gonokami, Urara Ikeda, Jin Funahashi, Takuya Oikawa, Rie Komai, Kayo Murai, Takako Shibasaki, Tsuyoshi Horikawa, Tetsuo Kato, Koji Tanaka, Akane Sato, Nao Inoue, Tomohito Nashi, Azusa Hara, Ryusuke Inoue, Kei Asayama, Hirohito Metoki, Masahiro Kikuya, and Kazuhito Totsune.

All names of participating practitioners have been previously published. ${ }^{15}$

This work was supported by grants for Scientific Research (1854042, 207477) from the Ministry of Education, Culture, Sports, Science and Technology, by Health Science Research Grants on Health Services (13072101, H12-Medical Care-002) from the Ministry of Health, Labour and Welfare, Junkanki-Byou-Itaku-Kenkyuhi (H19-Kou-8) from the National Cardiovascular Center and by Nouvelle Place, Japan.

1 Imai Y, Ohkubo T, Hozawa A, Tsuji I, Matsubara M, Araki T, Chonan K, Kikuya M, Satoh $\mathrm{H}$, Hisamichi S, Nagai K. Usefulness of home blood pressure measurements in assessing the effect of treatment in a single-blind placebo-controlled open trial. J Hypertens 2001; 19: 179-185.

2 Ohkubo T, Asayama K, Kikuya M, Metoki H, Hoshi H, Hashimoto J, Totsune K, Satoh H, Imai Y. Ohasama Study. How many times should blood pressure be measured at home for better prediction of stroke risk? Ten-year follow-up results from the Ohasama study. J Hypertens 2004; 22: 1099-1104.

3 Bobrie G, Chatellier G, Genes N, Clerson P, Vaur L, Vaisse B, Menard J, Mallion JM. Cardiovascular prognosis of 'masked hypertension' detected by blood pressure self-measurement in elderly treated hypertensive patients. JAMA 2004; 291: 1342-1349.

4 Mallion JM, Clerson P, Bobrie G, Genes N, Vaisse B, Chatellier G. Reply to the article: definition of masked hypertension [Letter]. J Hypertens 2007; 25: 1511-1513.

5 Parati G, Stergiou GS, Asmar R, Bilo G, de Leeuw P, Imai Y, Kario K, Lurbe E, Manolis A, Mengden T, O'Brien E, Ohkubo T, Padfield P, Palatini P, Pickering T, Redon J, Revera M, Ruilope LM, Shennan A, Staessen JA, Tisler A, Waeber B, Zanchetti A, Mancia G. ESH Working Group on Blood Pressure Monitoring. European Society of Hypertension guidelines for blood pressure monitoring at home: a summary report of the Second International Consensus Conference on Home Blood Pressure Monitoring. J Hypertens 2008; 26: 1505-1526.

6 Pickering TG, Miller NH, Ogedegbe G, Krakoff LR, Artinian NT, Goff D. American Heart Association; American Society of Hypertension; Preventive Cardiovascular Nurses Association. Call to action on use and reimbursement for home blood pressure monitoring: a joint scientific statement from the American Heart Association, American Society of Hypertension, and Preventive Cardiovascular Nurses Association. Hypertension 2008; 52: 10-29.

7 Imai Y, Otsuka K, Kawano Y, Shimada K, Hayashi H, Tochikubo O, Miyakawa M, Fukiyama K. Japanese Society of Hypertension. Japanese Society of Hypertension (JSH) guidelines for self-monitoring of blood pressure at home. Hypertens Res 2003; 26: 771-782

8 Asayama K, Ohkubo T, Kikuya M, Obara T, Metoki H, Inoue R, Hara A, Hirose T, Hoshi $\mathrm{H}$, Hashimoto J, Totsune K, Satoh H, Imai Y. Prediction of stroke by home 'morning' versus 'evening' blood pressure values: the Ohasama study. Hypertension 2006; 48: 737-743.

9 Kario K, Ishikawa J, Pickering TG, Hoshide S, Eguchi K, Morinari M, Hoshide Y, Kuroda $\mathrm{T}$, Shimada K. Morning hypertension: the strongest independent risk factor for stroke in elderly hypertensive patients. Hypertens Res 2006; 29: 581-587.

10 Shibuya Y, Ikeda T, Gomi T. Morning rise of blood pressure assessed by home blood pressure monitoring is associated with left ventricular hypertrophy in hypertensive patients receiving long-term antihypertensive medication. Hypertens Res 2007; 30: 903-911.

11 Ikeda T, Gomi T, Shibuya Y, Matsuo K, Kosugi T, Oku N, Uetake Y, Kinugasa S, Furutera R. Morning rise in blood pressure is a predictor of left ventricular hypertrophy in treated hypertensive patients. Hypertens Res 2004; 27: 939-946.

12 Ishikawa J, Hoshide S, Shibasaki S, Matsui Y, Kabutoya T, Eguchi K, Ishikawa S, Pickering TG, Shimada K, Kario K. JMS-1 Study Group. Relationship between morning hypertension identified by home blood pressure monitoring and brain natriuretic peptide and estimated glomerular filtration rate: the Japan Morning Surge 1 (JMS-1) Study. I Clin Hypertens (Greenwich) 2008; 10: 34-42.

13 Kawabe H, Saito I, Saruta T. Status of home blood pressure measured in morning and evening: evaluation in normotensives and hypertensives in Japanese urban population. Hypertens Res 2005; 28: 491-498.

14 Asayama K, Ohkubo T, Hara A, Hirose T, Yasui D, Obara T, Metoki H, Inoue R, Kikuya M, Totsune K, Hoshi H, Satoh H, Imai Y. Repeated evening home blood pressure measurement improves prognostic significance for stroke: a 12-year follow-up of the Ohasama study. Blood Press Monit 2009; 14: 93-98.

15 Ohkubo T, Obara T, Funahashi J, Kikuya M, Asayama K, Metoki H, Inoue R, Kikuya M, Totsune K, Hoshi H, Satoh H, Imai Y. J-HOME Study Group. Control of blood pressure as measured at home and office, and comparison with physicians' assessment of control among treated hypertensive patients in Japan: first report of the J-HOME study. Hypertens Res 2004; 27: 755-763.

16 Obara T, Ohkubo T, Funahashi J, Kikuya M, Asayama K, Metoki H, Oikawa T, Hashimoto $\mathrm{J}$, Totsune K, Imai Y. Isolated uncontrolled hypertension at home and in the office among treated hypertensive patients from the J-HOME study. $J$ Hypertens 2005; 23: $1653-1660$

17 Shirasaki O, Terada H, Niwano K, Nakanishi T, Kanai M, Miyawaki Y, Souma T, Tanaka T, Kusunoki T. The Japan Home Health Apparatus Industrial Association: investigation of home-use electronic sphygmomanometers. Blood Press Monit 2001; 6: 303-307.

18 Association for the Advancement of Medical Instrumentation. American National Standard for Electronic or Automated Sphygnomanometers, AAMI Analysis and Review. Association for the Advancement of Medical Instrumentation: Washington DC, 1987.

19 Japanese Society of Hypertension. Japanese Society of Hypertension guidelines for the management of hypertension (JSH2009). Hypertens Res 2009; 29: 1-107.

20 Mancia G, De Backer G, Dominiczak A, Cifkova R, Fagard R, Germano G, Grassi G, Heagerty AM, Kjeldsen SE, Laurent S, Narkiewicz K, Ruilope L, Rynkiewicz A, Schmieder RE, Boudier HA, Zanchetti A, Vahanian A, Camm J, De Caterina R, Dean V, Dickstein K, Filippatos G, Funck-Brentano C, Hellemans I, Kristensen SD, McGregor K, Sechtem U, Silber S, Tendera M, Widimsky P, Zamorano JL, Erdine S, Kiowski W, Agabiti-Rosei E, Ambrosioni E, Lindholm LH, Viigimaa M, Adamopoulos S, AgabitiRosei E, Ambrosioni E, Bertomeu V, Clement D, Erdine S, Farsang C, Gaita D, Lip G, Mallion JM, Manolis AJ, Nilsson PM, O'Brien E, Ponikowski P, Redon J, Ruschitzka F, Tamargo J, van Zwieten P, Waeber B, Williams B. Management of Arterial Hypertension of the European Society of Hypertension; European Society of Cardiology. 2007 Guidelines for the Management of Arterial Hypertension: The Task Force for the Management of Arterial Hypertension of the European Society of Hypertension (ESH) and of the European Society of Cardiology (ESC). J Hypertens 2007; 25: 1105-1187.

21 Chobanian AV, Bakris GL, Black HR, Cushman WC, Green LA, Izzo Jr JL, Jones DW, Materson BJ, Oparil S, Wright Jr JT, Roccella EJ. National Heart, Lung, and Blood 
Institute Joint National Committee on Prevention, Detection, Evaluation, and Treatment of High Blood Pressure; National High Blood Pressure Education Program Coordinating Committee. The Seventh Report of the Joint National Committee on Prevention, Detection, Evaluation and Treatment of High Brood Pressure: the JNC 7 Report. JAMA 2003; 289: 2560-2572.

22 Obara T, Ohkubo T, Asayama K, Metoki H, Inoue R, Kikuya M, Kato T, Tanaka K, Hara A, Hashimoto J, Totsune K, Imai Y. J-HOME Study Group. Home blood pressure measurements associated with better blood pressure control: the J-HOME study. J Hum Hypertens 2008; 22: 197-204.

23 Kawano Y, Pontes CS, Abe H, Takishita S, Omae T. Effects of alcohol consumption and restriction on home blood pressure in hypertensive patients: serial change in the morning and evening records. Clin Exp Hypertens 2002; 24: 33-39.

24 Rosito GA, Fuchs FD, Duncan BB. Dose-dependent biphasic effect of ethanol on 24-h blood pressure in normotensive subjects. Am J Hypertens 1999; 12: 236-240.

25 Kawano Y, Abe H, Kojima S, Ashida T, Yoshida K, Imanishi M, Yoshimi H, Kimura G, Kuramochi M, Omae T. Acute depressor effect of alcohol in patients with essential hypertension. Hypertension 1992; 20: 219-226.

26 MacMahon S. Alcohol consumption and hypertension. Hypertension 1987; 9 : $111-121$.

27 Kawabe H, Saito I. Influence of nighttime bathing on evening home blood pressure measurements: how long should the interval be after bathing? Hypertens Res 2006; 29: 129-133.

28 Daly PA, Landsberg L. Hypertension in obesity and NIDDM. Role of insulin and sympathetic nervous system. Diabetes Care 1991; 14: 240-248.

29 Baron AD. Insulin resistance and vascular function. J Diabetes Complications 2002; 16: 92-102.

30 Kawano H, Motoyama T, Hirashima O, Hirai N, Miyao Y, Sakamoto T, Kugiyama K, Ogawa $H$, Yasue $H$. Hyperglycemia rapidly suppresses flow-mediated endotheliumdependent vasodilation of brachial artery. J Am Coll Cardiol 1999; 34: 146-154.

31 Katayama S, Inaba M, Morita T, Awata T, Shimamoto K, Kikkawa R. Blood pressure control in Japanese hypertensives with or without type 2 diabetes mellitus. Hypertens Res 2000; 23: 601-605.
32 Bakris GL. A practical approach to achieving recommended blood pressure goals in diabetic patients. Arch Intern Med 2001; 161: 2661-2667.

33 Lewis EJ, Hunsicker LG, Clarke WR, Berl T, Pohl MA, Lewis JB, Ritz E, Atkins RC, Rohde R, Raz I. Collaborative Study Group. Renoprotective effect of the angiotensinreceptor antagonist irbesartan in patients with nephropathy due to type 2 diabetes. $N$ Engl J Med 2001; 345: 851-860.

34 Chonan K, Hashimoto J, Ohkubo T, Tsuji I, Nagai K, Kikuya M, Hozawa A, Matsubara M, Suzuki M, Fujiwara T, Araki T, Satoh H, Hisamichi S, Imai Y. Insufficient duration of action of antihypertensive drugs mediates high blood pressure in the morning in hypertensive population: the Ohasama study. Clin Exp Hypertens 2002; 24: 261-275.

35 Kamoi K, Ikarashi T. The bedtime administration of doxazosin controls morning hypertension and albuminuria in patients with type- 2 diabetes: evaluation using home-based blood pressure measurements. Clin Exp Hypertens 2005; 27: 369-376.

36 Kario K, Matsui Y, Shibasaki S, Eguchi K, Ishikawa J, Hoshide S, Ishikawa S, Kabutoya T, Schwartz JE, Pickering TG, Shimada K. Japan Morning Surge-1 (JMS-1) Study Group. An alpha-adrenergic blocker titrated by self-measured blood pressure recordings lowered blood pressure and microalbuminuria in patients with morning hypertension: the Japan Morning Surge-1 Study. J Hypertens 2008; 26: 1257-1265.

37 Oikawa T, Obara T, Ohkubo T, Kikuya M, Asayama K, Metoki H, Komai R, Murai K, Hashimoto J, Totsune K, Imai Y. J-HOME Study Group. Characteristics of resistant hypertension determined by self-measured blood pressure at home and office blood pressure measurements: the J-HOME study. J Hypertens 2006; 24: 1737-1743.

38 Ashida T, Sugiyama T, Okuno S, Ebihara A, Fujii J. Relationship between home blood pressure measurement and medication compliance and name recognition of antihypertensive drugs. Hypertens Res 2000; 23: 21-24.

39 Marquez-Contreras E, Martell-Claros N, Gil-Guillen V, de la Figuera-Von Wichmann M, Casado-Martỳ'nez JJ, Martin-de Pablos JL, Figueras M, Galera J, Serra A, Compliance Group of the Spanish Society of Hypertension (SEE). Efficacy of a home blood pressure monitoring programme on therapeutic compliance in hypertension: the EAPACUM-HTA study. J Hypertens 2006; 2: 169-175. 